\title{
China: The Epidemiology of Mental Illness
}

\section{ARTHUR KLEINMAN}

The period of societal transformation that China has undergone from the First Opium War (1839-42) to the current day can only be thought of as immense and spectacular. Under the brutal force of foreign imperialism combined with disintegration of first the Qing court and later the Republic, China became "the sick man of Asia" with extraordinarily high child and adult mortality, widespread chronic starvation, enormous numbers of the displaced, political chaos, desperate personal accounts, and a collective sense of national shame. It is worth remembering that during the Second World War, which lasted from 1937-1945 in China, there were 20 million killed and tens of millions uprooted. What the long-term traumatic consequences of this history has been, no one knows. What impact it has on mental health in China is also uncertain. There are no authoritative data that document the magnitude and distribution of mental health problems for the tumultuous and tragic times that preceded the founding of the People's Republic in 1949.

In Taiwan, Tsung-yi Lin and his colleagues at the National Taiwan University's Department of Psychiatry initiated a long-term epidemiological project running from 1946 through the 1970s that showed a substantial increase in neuroses during those decades of extremely rapid political and economic transformation, during which a poor agricultural society turned into a wealthy industrial state (Yeh et al, 1987). Rates of psychoses did not demonstrate much change, a finding frequently cited by those who argue for their genetic determination. Regardless if one thinks of Taiwan as part of or separate from the Chinese state, the experience of its Han Chinese people has been very different, and therefore the social conditions of mental health are not truly comparable.

In the late 1950s during the first decade of the People's Republic, early efforts were made to determine the rates of mental illnesses around Beijing and Changsha, and in the 1970s other epidemiological studies were initiated throughout China. These were years during which mortality owing to infectious disease was greatly reduced, social stability was secured, housing and jobs made broadly available, medical services expanded, and hunger substantially, though not entirely, eliminated. But the very political policies that produced these health-enhancing results also created the world's most deadly famine - from 1959-61, at least 30 million and perhaps more than $\mathbf{4 0}$ million died as a result - and the almost complete chaos of the Cultural Revolution. In 1978, Deng Xiaoping introduced a new policy of economic reforms that by 1996 has made China's economy not only the fastest growing in the world but the third largest as measured by purchasing power parity. There has been a revolution in popular culture, in globalisation, in every day social life, especially for the $\mathbf{2 0 0}$ million Chinese who live along the coastal edge and are participating in one of East Asia's tiger economies. Those 800 million who live inland are experiencing a slower but still impressive growth in political economy and, therefore, in their living conditions. Somewhere between 100-150 million of them have become economic migrants, part of the "floating" population that lives at the margins of China's most flourishing cities. They are at risk for poor housing and violence, but many have improved their financial situation. The $\mathbf{2 0 0}$ million "other" Chinese who inhabit China's poorest rural areas still live in degrading poverty, however, under conditions that have changed little not only since 1949, but perhaps since the fall of the Qing dynasty in 1912. Thus, the country we call China is an immense, heterogeneous, rapidly changing society whose peoples have experienced powerful and contradictory social forces. How those forces affect individuals' mental health outcomes is of great consequence, as is the knowledge of what are the limits of that influence. For example which rates of neuropsychiatric disease are principally determined by genetic endowment?

In 1982, early in the current period of economic reform, Chinese psychiatrists, with the assistance of the Mental Health Programme at the World Health Organization, initiated and coordinated an impressively large epidemiological survey of 51982 persons in 12 very different sites, that have both urban and rural areas. The data from this study have been known, in part at least, for some time in China, but now the overall results are available in a book, Mental Disorders in China, by two well-known Western psychiatrists who participated in the effort, 
John Cooper and Norman Sartorius. While Professors Cooper and Sartorius are to be congratulated for editing this material, the work is principally the achievement of Chinese psychiatrists - some well known, others not so well known - in 12 centres in China. We owe them a great debt. For, in spite of the obvious fact that the findings cannot tell us exactly how mental health problems in the world's largest country reflect (or resist) the social history I have sketched, they raise many interesting comparative cross-cultural questions, offer some important foundations for future research, and are practically important for the organisation of health services. Moreover, an effort was made to provide data that are culturally appropriate: the Chinese national classification system was used as the basis for diagnosis together with ICD-9, experienced Chinese psychiatrists participated at all levels of the study, and care was taken in the translation of instruments to assure cross-cultural comparability.

The findings that stand out are the overall low prevalence rate of mental illness (rates 3-5 times lower than in the West) and the often substantial differences across the different centres (three-fold difference across highest and lowest populations for psychotic disorders and five-fold for neuroses) that point to the salience of heterogeneity. Also notable are: the higher rate of schizophrenia in women; the relation of better outcome for schizophrenia patients with family's higher economic status; the relatively large percentage of schizophrenic patients $(20 \%)$ that received "no treatment at all"; and the estimate, based on earlier studies, that the prevalence of schizophrenia seems to have increased. For neurotic disorders, which also are of much lower prevalence than in Western Europe and North America, striking is the nine-fold higher rate for women as well as very low rates of depressive and anxiety disorders and alcoholism, and the high rate of neurasthenia. The editors conclude that the last appears to imply "neurosis" rather than a specific disease entity because of the lack of specificity of symptoms (some are vague and patternless, while others were rated as somatic symptoms of depression). The correlation of prevalence rates of mental retardation with surrogate measures of class is not novel in itself; but it is interesting because of what it says of the stability of such social divisions and their consequences in a Communist state that about the time of this study substituted increasing wealth in general for class-based advancement as its ideology. Although reflecting different methods and nosology, the editors are also right to remark on the two- to four-fold increase in rates of mental disorders since surveys in the 1960 s.

How to make sense of it all is another matter altogether. It is hard to imagine the Chinese ever went through more difficult times than the Great Famine and the Cultural Revolution. If social changes matter then surely it is not straightforward that they are exerting a greater effect now, as the editors appear to conclude. The Chinese Classification of Mental Illness, 2nd Revision (CCMD-II) came on line after this study. All over China, rates of depressive and anxiety disorders have gone up while rates of neurasthenia have decreased (but not disappeared) under this new classification. The World Bank data on suicide in China give a much higher rate than that in the 1982 survey, as do their data for the burden of neuropsychiatric disability overall in China (World Development Report, 1993). The findings also do not show the emerging epidemic of illicit drugs that together with violence has been reported for those Chinese populations that border the "Golden Triangle" and among the floating population in the booming coastal cities (Desjarlais et al, 1995). Nor can we be entirely sure, in spite of the fascinating findings, which mental health conditions are unrelated to changing social conditions and which are shaped by particular conditions, even though the data point in general to a strong influence of political economy and robust cross-cultural variation. So readers are advised to treat these findings carefully and respect all the qualifications. This is not the last word on mental illness in China's one-fifth of humankind or even the latest. But it is an important, particularly welldocumented point from which to look at the pluralism as well as the similarities and to be sensitive to the complexity of mental health conditions.

\section{Roferences}

COOpre, J. \& SARtorrus, N. (eds) (1996) Mental Disorders in China. London: Gaskell.

Dessarlais, R., et al (ods) (1995) World Mental Health: Problems and Priorities in Low-Income Countries. New York: Oxford Univeraity Press.

World Develominant Report (1993) Investing in Health. New York: Oxford University Press for the World Bank.

YEH, E. K., et al (1987) Social changes and prevalence of specific mental disorders in Taiwan. Chinese Journal of Mental Health, 3, 31-42.

Professor A. Kleinman, Departments of Anthropology and Social Medicine, Harvard University, Wm. James Hall 300, Cambridge, MA 02138, USA. Fax: 617/495 3557 